\title{
Electro Organic Synthesis Utilizing Mg Electrodes (II) - Novel Synthesis of Symmetric Azobenzenes from Nitrobenzenes -
}

\author{
Soonki Won, Wanjoong Kim, and Hongbum Kim \\ Deparment of Chemishy, College of Nathral Science, Dongguk University, Seoul 100-715, Korea. ${ }^{\dagger}$ E-mail honghum(i)dgutedu \\ Received September 14,2005
}

Key Words : Electro organic synthesis, Electro reductive coupling, $\mathrm{Mg}$ electrode, $\Lambda$ zo compounds

On the way to study electro organic synthesis (EOS) ${ }^{1.2}$ utilizing alternating $\mathrm{Mg}$ electrodes, a novel synthetic route from the nitrobenzenes 10 symmetric ayobenzenes was discovered in our laboratory.

The brief review aboul COS was introduced by us. "The COS is expected to be an important organic synthetic tool in luture because of its diverse application in industry in addition to compatibility with green chemistry. ${ }^{4.5}$ In the previous paper ${ }_{4}^{3}$ we reported the optimized reaction conditions for the electro reductive coupling of aromatic halides: $\mathrm{Mg}$ rod for both of anode and cathode under a constant current, ${ }^{6} \mathrm{LiClO}_{4}$ as a clecirolyle, TIJF or glyme as a solvent.

We have tried to extend EOS to other lunctional groups. Since nitrobenzenes were readily reduced under the various mild reaction conditions, we exposed several nitrobenzenes under EOS reaction conditions. Our reaction conditions were $\mathrm{Mg}$ for anode and cathode, $\mathrm{LiClO}_{4}, \mathrm{TIJF}$, room temperature under a constant current (current density -42 $\mathrm{m} \Lambda / \mathrm{cm}^{2}$ ). The currents of anode and cathode were alternated at an interval of 30 seconds in order to minimize the consumption of the metal. The reaction mixture was carefully monitored by TLC and then worked up when nitrobenzene 1 was completely disappeared. The new spot was isolated and characterized fully by TLC and spectroscopic methods with an authentic sample. To our surprise, it was azoberwene 2 instiad of aniline 3 based on the previously reported paper. ${ }^{\varnothing}$ The optimized yicld of 2 was $87.6 \%$ with no trace of the desired aniline 3 . The amount of $\mathrm{Mg}$ consumed during the ruction was less then $5.0 \%$ for every altempt (ca. 1).

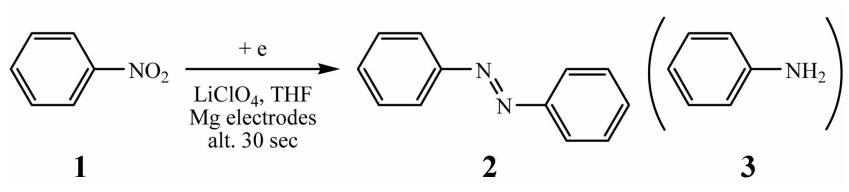

With the novel azo synthetic method in our hand, the various nitrotoluenes were submitted under our optimized reaction conditions (Table 1). ${ }^{9.10}$

In general, the nitrotoluenes gave rise to the corresponding a $\%$ products in reasonable yiclds. It is noteworthy obscrvation that o-nitrotoluene gave products in about $30 \%$ lower yield compared to others due to possible steric hinderance in these electro organic reaction. Since $p$-nitrotoluene provided
Table 1. Ilectro Reduclive Coupling Reaction of Nitrobenzenes

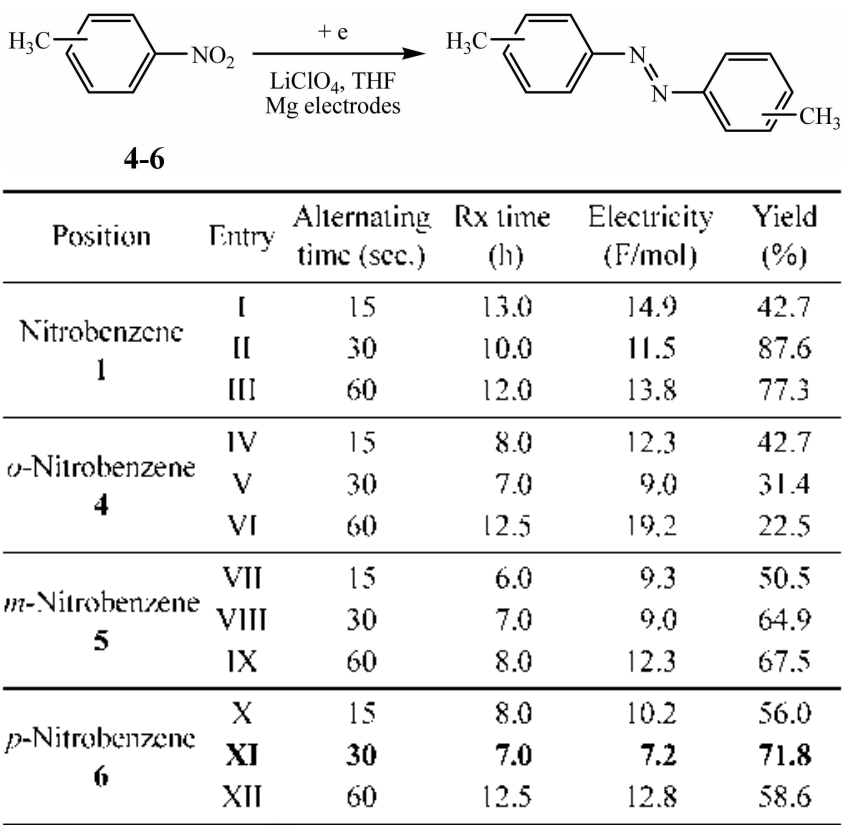

'All reactions uere performed at foom temperature.

Table 2. Ilectro Reduclive Coupling Reaction of p-Nitrololuene

\begin{tabular}{|c|c|c|c|c|}
\hline & 6 & & 7 & \\
\hline Enlry & $\begin{array}{c}\text { Amount of } \\
\mathrm{LiClO}_{1}(\mathrm{cq})\end{array}$ & $\begin{array}{l}\text { Rx time } \\
\text { (h) }\end{array}$ & $\begin{array}{c}\text { Electricity } \\
(\text { (F/mol) }\end{array}$ & $\begin{array}{l}\text { Yicld } \\
(\%)\end{array}$ \\
\hline I & 5 & 7 & 7.2 & 71.8 \\
\hline II & 6 & 6 & 12.3 & 73.6 \\
\hline III & 8.2 & 2.5 & 6.4 & 85.3 \\
\hline
\end{tabular}

${ }^{\circ} \mathrm{All}$ reactions uere performed at foom temperature.

the highest yield and the lastest reaction time (Tnitry XI), it was selected to further refining reaction condition about the amount of an electrolyle (Table 2).

The yicld was progressively improved and the reaction time was significantly shortened as the amount of electrolyce was increased. The amount of electrolyte could not be increased more than 8.2 equivalent because of its limitation of solubility in THF. We assumed that the more electrolyte provided more electricity to improve the reaction yicld 


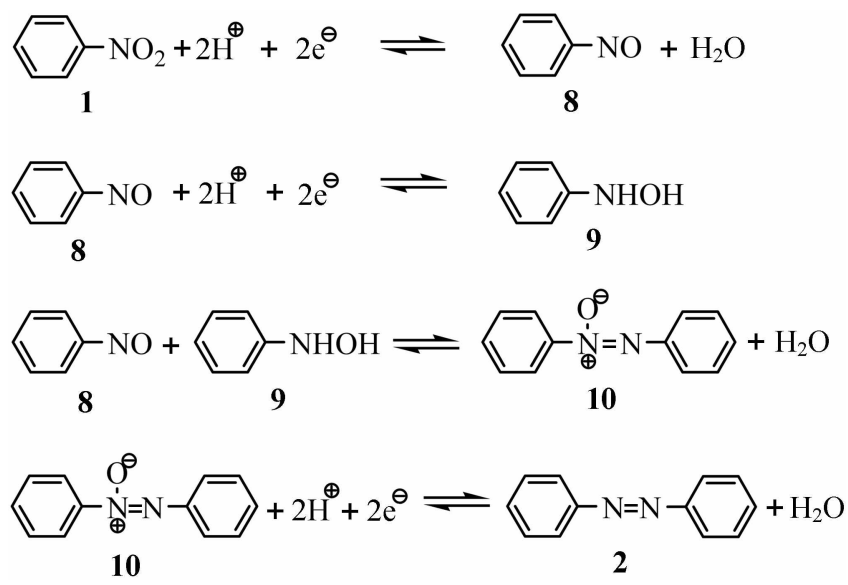

Scheme 1. The reduction mechanism of nitrobenzene.

and to shorten the reaction time.

Based on extensive litcrature search for electro reductive organic reaction of nitrobenzenes, our novel azo synthetic route can be rationalized by the following reaction mechanism (Scheme 1).

Nitrobenzene 1 was reduced to nitrosobenzene 8 by twoelectron reduction. A part of nitrosoben/ene 8 was reduced to phenylhydroxylamine 9 by two-electron reduction, ${ }^{1.12}$ Then axoxybenzene 10 was produced by coupling of 8 and 9 at the surface of the electrode. And reduction of the resulting 10 gave rise to the symmetrical azobenzene $2 .{ }^{13}$ In order to contirm the proposed reaction mechanism, we are trying to isolate the reactive intermediates $-8,9,10$ - in the course of our reaction and to use the commercially available 8 as a starting material.

The new synthetic route for the azo compounds is important sinee the azo compounds in addition to usage as classical dyes ${ }^{1.4}$ are remplasized as optical recording materials and nonlinear optical materials. ${ }^{15}$ A $\%$ compounds also are expect to be used photochromic dendrimers ${ }^{16}$ because molecular structure can be changed by light. The several unconventional methods for synthesis of the azo compounds - for example, nitrobenzene in carbone monoxide under 3000 atm at $250{ }^{\circ} \mathrm{C}$ by $\mathrm{Kmiecik}^{17}$ and catalytic transfer hydrogenation of nitrobenzene in methanol with lead as a catalyst by Gowda" ${ }^{18}$ - were reported but their reaction conditions were too harsh to do in the laboratory.

Our novel single synthetic route will provide more convenient and efficient procedure than the traditional azo synthesis from nitrobenzene. Our procedure will be easily applied for industrial process with compatibility in environmental concern.

In summary, the symmetric azobenzenes were synthesized from the nitrobenzenes in a single step by utilizing electro organic synthesis (EOS). The Mg electrodes were recovered more than $95 \%$ at the end of reaction. Under the optimized reaction conditions we developed, various nitrobenzenes are currently examined in our laboratory with substituents on the ring including electron donating group as $-\mathrm{CH}_{3},-\mathrm{NH}_{2}$,
$-\mathrm{OH}$ and electron withdrawing group as $-\mathrm{NO}_{2},-\mathrm{CO}_{2} \mathrm{R},-\mathrm{X}$. The further elucidation of reaction mechanism and its general application to other carbon skelecons are currently under investigation in our laboratory and will be discussed in due course.

Acknowledgement. We are grateful for generous financial support from KOSEF research project No. R 0l2001-000-00057-0 and thank Deogkeun Kweon for her assistance in early stage of our research.

\section{References and Notes}

I. Fry, A. J. Aldrichimica Acto 1993, 26, 3 .

2. Shono, T. Electroorganic Sinthesis; Academic Press: New York, 1991 .

3. Kweon, L.: Jang, Y,; Kim, H. Bull. Korem Chen. Soc. 2003, 24. 1049.

4. Matthews, M. Pufe Apml. Chtm. 2001, 73, 1305.

5. Steckhan, E.: Arns. T.: I leineman, C. Chenosphere 2001, 43, 63.

6. Kashimura, S.; Shono. T. J. Org. Chem. 1999, 64, 6615 .

7. Matsui, T.; Takeyarna, K. Elecfrochimica Acta 1998, 43, 1355.

8. Fry, A. J. Sinthetic Opganic Electrochemistm, 2nd ed.; John Wiley \& Sons, Inc.: New York, 1989; p 189.

9. Typical procedure is the following : $1 . \mathrm{iClO}+(3.90 \mathrm{~g} .36 .7 \mathrm{mmol}$, $4.5 \mathrm{I}$ eq. ) and $40 \mathrm{~mL}$ of THF were added to three neck jacket reactor equipped with Mg electrodes $(1 \times 0.5 \times 4 \mathrm{~cm})$ for both cathode and anode fitted with conderser in argon atmosphere. The reaction mixture was continuously stirted till all $\mathrm{LiClO}$. was dissolved. Nitrobenzene $1(1.00 \mathrm{~g} .8 .12 \mathrm{mmol}, 1.00 \mathrm{eq}$.) in $20 \mathrm{~mL}$ of THI solution was added by syringe pump for 1 hour. The constant current was supplied with Takasako (iPO) 50-2 regulated DC. power supply. $\left(50 \mathrm{~V}, 350 \mathrm{~m} \Lambda\right.$, current density $\left.=42 \mathrm{m \Lambda} / \mathrm{cm}^{2}\right)$ During the electro reduction, the polarity of the electrode was altered with an interval of 30 second using a alternator. The progress of the reaction was monitored by TLC. After confirm that nitrobenzene 1 disappears in reaction mixture by TI.C, ice cold $1.0 \mathrm{M} \mathrm{HCl} 30 \mathrm{~mL}$, was poured into the reaction mixture. The aqueous solution was extracted with diethyl ether $(20 \mathrm{~mL} \times 2)$. The combined organic layers were washed with $30 \mathrm{~mL}$ of brine, dried over $\mathrm{MgSO}_{\text {and }}$ ancentrated in vawo. The residue was purified by silica gel column, as ethyl acetate : hexane $(1: 40)$ as eluent gave rise to the arobenzene $2(87.6 \%)$. After reaction linished, My was recovered more than $95.0 \%$ by subsequent cleaning with $\mathrm{H}_{2} \mathrm{O}$ and $1.0 \mathrm{M} \mathrm{HCl}$.

10. All compounds were isolated and characterized fully by comparison TLC and by spectroscopic methods with authentic samples.

11. Ileyrovsky, W.; Vavricka, S. J. Electrowat. Chem. 1970, 28, 409 .

12. (a) Chiappardi, D. M.; Blount, I. N. J. Phws. Chem. 1982, 86, 2632. (b) Karakus, C.: 7.man, P..J. Electrokial ( $h \mathrm{~cm}$ 1995, 396, 499 .

13. (a) Lund, H.; Hammerich, O. Orgemic Electrochemistry; Marcel Dekker, Inc.: New York. 2000; p 390. (b) Fuy, A. I. at al. Smmeric Organic Tlectrochemistri, 2nded.; John Wiley \& Sons, lne.: New York, 1989; p 193.

14. Wang, M.; Funabiki, K.; Matsui, M. Dyes and Pigments 2003, 57 , 77.

15. Hornak, A; Weidman, W.; Kwock. W. J. Apt. Phys. 1990, 67, 2235.

16. T.iao, I.,; Junge, D. M.; McGirath. D. V. Macrontolectles 2002, 35, 319.

17. Kmiecik, E. J. Org. Chem. 1965, 30, 2014.

18. Abira, K.: Channe Gowda, D. Tetrethedron Lett. 2003, 44, 5835. 